\title{
Constructing an Interdisciplinary Peer Mentoring Network for First Year Faculty
}

\author{
Rebecca A. Bates \\ Minnesota State University, Mankato
}

\begin{abstract}
The success of a first year faculty member depends on many things, both internal (inherent to the person) and external. Given a record of success, i.e., many years of schooling and completion of a $\mathrm{Ph}$.D., the internal factors contributing to success are already available to most faculty members. The external factors that contributed to this earlier success may be difficult to duplicate at the new home institution. Along with information about mentoring in general, this paper presents one method of building an external network that will contribute to the success (and retention) of first year faculty.
\end{abstract}

\section{Introduction}

Success as a graduate student happens in part because of peer support, in the form of lab meetings, interaction in class and other academic settings, and during social activities, whether formally organized or not. Moving to an academic position can be an isolating experience both professionally and socially, particularly when the position is in a small department or in a department with few or no new faculty. While some departments or colleges may have a formal mentoring program or support informal mentoring, mentors are typically tenured faculty or people much further along in the tenure process. For a successful transition from student to faculty member, it is also important to build connections with faculty who are having similar experiences during a similar time frame. The need for connections and the potential lack of possibilities inside a home department suggest looking outside of engineering and science departments to find peers. Peer mentoring is accepted as useful for students, and the same benefits that come from learning from others are valuable for new faculty. By seeking interdisciplinary peers, the effects of "data" sparsity are reduced, especially since problems faced by first year teachers are rarely discipline-specific. New faculty benefit from multiple information channels about their institutions. In addition, discussions about teaching among an interdisciplinary group show that science and engineering faculty can benefit from experiences in the arts, humanities and social sciences.

This paper first describes some of the key issues for faculty success. Information is presented about the importance of mentoring, especially for underrepresented faculty where the decision to remain at a particular university may boil down to the social and personal connections they are able to make in a new location. In particular, motivation for and information about the usefulness of an interdisciplinary network will be presented. This work will describe the interactions of a group of faculty from multiple colleges at a teaching-focused university. 


\section{Key Issues for Faculty Success}

Faculty success is typically defined by the basic requirements for tenure: teaching, research, and service. These boil down to the ability to 1) create engaging courses where students learn the required content as well as skills that will help them successfully navigate their own careers, 2) write successful proposals and guide students through the research process, and 3) participate in committees and advise students without reducing the completion of the first two activities. While the weights placed on these areas may shift depending on the institution's focus, these factors, and possibly others, define success as measured by the carrot placed in front of most new hires: tenure. However, tenure alone is not sufficient for a successful and satisfying career, and new faculty who approach their careers with a focus on achieving tenure may or may not end up with career longevity and satisfaction. Therefore, along with the definition of success that includes adequate teaching and service and meeting the research bar in terms of funding and publication, it is worth including such things as job satisfaction, job retention, and overall satisfaction with one's life and career choice since most people teaching at the college level do have career options outside of academia.

The idea of collegiality and beneficial socialization into the academy are not new but are worth keeping in mind when discussing the first year of a faculty career. The climate a faculty member walks into is not something that is likely to be changed by that individual, especially in his or her first year. If what is found in the first year is "isolation, insecurity, and busyness" or feeling "overloaded, unsupported and uninformed" as described by Boice ${ }^{1}$, then addressing these issues at all levels may be the best solution. While the "quick-starter" characteristics of writing regularly, integrating research into lectures and limiting time for lecture preparation are useful guidelines, Boice's finding of the importance of social networking is best addressed here. The need for intellectual stimulation and collegial support is one that new faculty should be aware of and one that can be addressed by individuals. While not everyone may need or want social connections, for the author, it is an important part of a decision to remain at an institution.

\section{Faculty Mentoring in Engineering}

There are many papers and many anecdotal experiences that motivate the practice of mentoring and describe ways it can be done. At the institutional level, formal mentoring programs that pair senior and junior faculty can be instituted. ${ }^{2,3,4}$ At the departmental level, senior faculty can be aware of the need for mentoring as well as what information might be useful for new faculty. ${ }^{5}$ Useful examples are included in the reference section, especially the recent proceedings of a mentoring workshop held in $2004{ }^{6}$

Various authors have reported that women in academia benefit from having networking types of mentoring relationships. ${ }^{7,8,9,10}$ This has certainly been the author's experience, partly because no single mentor can provide guidance for every issue that arises. It simultaneously reduces the responsibility of any single mentor and reduces the expectation that a single mentor will be able to advise, guide or support a mentee in every situation. In an evaluation of mentor/mentee relationships, Marino \& Yost summarized that mentees need to seek out mentors and develop the relationship while mentors "must become more aware of the needs of new faculty and the benefits of assisting them in their adjustment to university positions." " As mentees, it cannot be assumed that mentors automatically have this awareness. Distributing the mentoring tasks by seeking guidance and advice from multiple mentors can reduce negative experiences (e.g., as 
reported by Marino \& Yost ${ }^{11}$ and Wasburn \& LaLopa ${ }^{4}$ ) associated with formally-assigned mentors.

\section{Peer Mentoring}

The value of peer mentoring is established at the student level. ${ }^{12,13,14,15}$ For faculty members, the focus has been on having a senior mentor who can guide, advise, support and advocate for the mentee. For first-year faculty members (as well as those on the path to tenure), it can be equally important to be in contact with peers going through the same or similar experiences. One of the recommendations for the Purdue University Faculty Mentoring Network, a formal mentoring program that paired first year faculty with more senior faculty, was to add group sessions and encourage exchanges among pairs in order to create a network, especially among mentees. ${ }^{4}$ Peers from other disciplines on the same campus are also valuable in that a group of peers may be better able to map the political landscape of a university than a single faculty member whose primary connections are to his or her home department. While many faculty members may have friends from graduate school who are at a similar stage in a faculty career and who could share experiences, this does not address the issue of physical isolation that may arise. For example, on-campus peers can help address the issue of learning to live in a small town with few obvious social or cultural outlets. By creating a network of mentors, both at the senior and peer levels, faculty members are not relying on a single person for information and support. A group spreads out the "work" of mentoring, an important aspect when all members are overwhelmed with new responsibilities, but all members reap the benefits of information passed through the cohort.

An important aspect of peer mentoring is the safety and comfort that may be felt when asking high-risk questions (such as questions that show how much trouble a new teacher is having with a particular course, topic or group of students). The fact that senior mentors may one day be in a position to judge junior faculty members (e.g. by voting on their tenure application) can make it difficult for the junior to confide in a mentor about difficulties they are having with teaching or advising research students. Peer mentors can share information received through experience or from other mentors without it feeling like an unsafe situation.

\section{Interdisciplinary Groups}

The primary benefit from forming interdisciplinary groups is that there is a greater chance of forming a group that meets the social and intellectual needs of the members than if membership only comes from a single academic department or college. If a department is large enough to have an entering cohort of new faculty, the group should be encouraged to meet regularly. Peer mentoring will happen as needed. In many cases, though, there may be only one new faculty member few non-tenured faculty. This leaves little room for the benefits of peer-mentoring.

Another benefit is being able to learn from the experiences of others and being introduced to ideas that are old hat in one community but potentially new (and useful) in others. Members of interdisciplinary groups benefit from having multiple information channels at their academic institution. In larger universities, knowing about administration differences may help in negotiations for compensation or release time. Coming into contact with people from other departments will also contribute to the atmosphere of ideas that stimulate any researcher and may inspire interdisciplinary research projects. One known benefit of having a mentor is help in integrating into the academic community. ${ }^{5}$ When viewed at multiple levels, integration into a 
departmental community, a college community, or a university community can be aided by mentors in different positions. Interdisciplinary mentors can facilitate the entry into a broader academic community with more ease than a single mentor.

An example of a formalized version of interdisciplinary groups is the generation of faculty learning communities. Usually with administrative support, groups of faculty are invited to spend a term or an academic year addressing a topic, typically related to teaching. Faculty may have to apply to join the community. Meetings are usually held monthly and common readings give the group initial cohesion. This activity can address the need for intellectual stimulation that may not be met when most of one's day is spent talking with undergraduate students.

\section{The Group Experience}

Minnesota State University, Mankato is a teaching-focused public university with six colleges, offering bachelor and masters degrees in 150 programs of study to about 14,000 students. Mankato, Minnesota, a community of about 45,000, is a "nice place to raise a family" and is famous for being the "big town" in the Little House on the Prairie series. Every fall, MSU has a week-long orientation for all new faculty (including fixed-term hires). During this week, typical new hire information is dispensed. More importantly, there is an opportunity to meet new faculty from the entire university.

This work describes a group of faculty who started at MSU in the fall of 2002. While some faculty were experienced teachers, many were true first year faculty. Some faculty had chosen to work at MSU because they were starting families. Others had chosen MSU because this was the type of institution where they wanted to teach. The orientation period gave faculty time to meet with others who may be potential collaborators on interdisciplinary work, whom they may be working with on college or university level, and, most pertinent here, may be in a similar social situation. Faculty members who were starting families (or with young families) had with them a built-in set of connections to the greater community. Experienced faculty often had close ties to the area that brought them back to this location. First year faculty without families (and who had typically spent the last few years focusing on their graduate work) did not start with these connections and were able to use this orientation time to meet faculty in similar positions.

At the end of the 2002 fall orientation, a cohort of ten was identified. This cohort was comprised of faculty from the College of Science, Engineering and Technology (3), the College of Arts and Humanities (5), and the College of Social and Behavorial Sciences (2). In most cases, the cohort members were the only new faculty in their department. Four members were on fixedterm appointments and three left after the first year. Previous teaching and research experience differed greatly among the cohort, with people bringing many different experiences. One member had ten years experience teaching high school classes, while others had "typical" experience with teaching as graduate students. Some had had some formal training in the form of teaching workshops, classes or mentored graduate student experiences. Most of the cohort were not married and had no dependents. While this may mean less responsibility to other individuals, there was also no assumed support network for most of the cohort.

During the middle of the first week of orientation, the group met at a local tavern and developed a plan to meet regularly. Along with the desire for social interaction, the feeling that we were all 
out of our familiar learning element lead to a grandiose plan to develop a philosophy reading group. However, as the semester progressed, the need for new academic challenges was greatly reduced, replaced by the more practical issues of figuring out how to explain what we knew to novice learners, how to give useful feedback to all of the students in our (up to 4 different) classes, and how to either 1) finish our dissertations, 2) make progress on publications, 3) navigate tricky department politics, or 4) set up research work while doing all of the above. Our weekly meetings were definitely social interactions but, more importantly, were informal interactions of peers with time to vent about problems, seek potential solutions and explore options in a very safe and comfortable environment.

While the initial motivation to build this network was a desire to avoid isolation, the benefit of the varied teaching experience and insight from others in the cohort was additional motivation to continue meeting as a group. A group with teaching experiences in a broad educational context meant that there were many ways of addressing issues that could be shared. For example, engaging students in a philosophy course is not that different from engaging students in a computer architecture course.

Throughout the first year, we had weekly meetings that allowed for social interaction as well as time and space to vent frustrations and share triumphs. When a member begged off because of too much work, there was still email contact with the rest of the cohort. Even this type of event allowed for mentoring that could have a positive impact on reducing the "busyness" of the first year. When some faculty members were obviously feeling overwhelmed with the volume of grading and lecture and assignment preparation, there were opportunities to share information that might help, including discussions of grading methods such as rubrics and check-brics or electronic submission of homework sets.

In a Machiavellian sense, this group of friends saved time. By developing local friendships that help to support our careers, our enjoyable social time was also used to develop strong professional connections. This interdisciplinary cohort has its own possibilities for future research directions: merging technology with arts, doing sociological research with women in science and engineering, building curricula that support multi-disciplinary teams (where disciplines go beyond the traditional engineering disciplines) and the understanding of the impact engineering solutions have in a global and societal context. ${ }^{16}$

While the group has changed composition, there is still contact among the original cohort. As newer faculty members make connections with our group, we have been able to maintain the cohort size and still provide a network of support for each other. This includes regular (weekly) gatherings. Our network is reflected in the growing connections to the larger community that have come from being directly connected to members of the cohort, whether it is knowledge of art openings and concerts or introductions to politically and socially active members of the greater community.

\section{Suggestions for Institutional Support}

First, it should be noted that the type of peer-mentoring described here is not a formal program sponsored in any way by the institution. However, there were some things that MSU did that supported the development of the group. The week-long orientation for all faculty members 
before the start of classes gave the faculty time to interact. More "white space" in the schedule would have been an additional encouragement. By including 15-20 minute breaks throughout the day, there is time for conversations amongst new faculty but not so much time that people might head back to their offices. By incorporating teacher training through things like active learning workshops, diverse groups of faculty would be able to interact and find colleagues with whom they may enjoy talking about teaching throughout their first year. Having a gathering at the beginning of the second semester would allow new faculty to reconnect with people they might not bump into regularly.

In addition, MSU now addresses some needs of new faculty with a formal mentoring program. The mentor/mentee pairs are assigned using the criteria that they share the same college (and thus hiring dean) but not the same department. In addition to the introductory reception and talk at the beginning of the year, hosting meetings of the large set of mentors and mentees during the academic year would contribute to the development of new groups of interdisciplinary peers. Another initiative that allows faculty to be involved with interdisciplinary groups is faculty learning communities on diverse topics (such as classroom assessment techniques, service learning, and feminist issues). These learning communities draw members from all departments of the university and promote faculty interaction. For the cost of refreshments at large and small group meetings, an institution can create situations that will lead to improved peer-mentoring.

\section{Other Resources}

Mentoring can happen in many forms. Along with developing relationships in one's home institution, it can be important to maintain earlier relationships and look to conferences and meetings to develop relationships with new mentors. At any point of change in a career, whether from graduate school to a faculty position, from one faculty step to another, or from faculty to an administrative position, mentors at the peer-level and above can help make the transition smoother. Additionally, there are many useful books available that can arm new faculty with knowledge about the system they are entering. Some of these are listed in the reference section. $^{17,18,19}$

\section{Summary}

The transition to a successful member of the academy can be supported in many ways by hiring institutions, through formal mentoring programs, encouraging informal mentoring and developing faculty learning communities. While first year faculty are encouraged to participate in these, it is also wise to develop supportive relationships within the broader institution community that can provide social interaction as well as a network for dealing with issues of teaching, research and service. Engineers and scientists who look beyond their departments and schools will find links to an enjoyable greater community as well as potential connections for truly interdisciplinary projects for themselves and their students.

\section{Acknowledgments}

The author wishes to thank Joyce Barry, Jeff Langstraat, Anne Lacsamana, Craig Matarrese, Sam Peterson, Jason Ruhl, Mary Lyn Stoll, Trent Vorlicek and Gina Wenger. Additionally, she thanks Dan Swart, Amanda Luyster, Mika Laidlaw, and Les Laidlaw. Thanks also to Maya Gupta and Tara Javidi for their stories. Thanks to Sarah Schwarm, Barb Bergman, Jessica Schomberg and Lee Cornell for comments. 


\section{References}

${ }^{1}$ R. Boice, The New Faculty Member, San Francisco: Jossey Bass, 1992.

${ }^{2}$ V. K. Varma \& T. Varma, "Important Steps to Skillful Mentoring of New Faculty: Avoiding the Pitfalls," Proc. of the 2001 ASEE Annual Conference \& Exposition.

${ }^{3}$ L. Hoffman, R. A. Aubrey, \& K. D. Taylor, "Mentoring for Success," Proc. of the 1998 ASEE Annual Conference \& Exposition.

${ }^{4}$ M. H. Wasburn \& J. M. LaLopa, “Assessing a Big Ten University’s Faculty Mentoring Network Program,” Proc. of the 2004 ASEE Annual Conference \& Exposition.

${ }^{5}$ R. Brent \& R. M. Felder, "Helping New Faculty Get Off to a Good Start," Proc. of the 2000 ASEE Annual Conference \& Exposition.

${ }^{6}$ Mentoring for Academic Careers in Engineering: Proceedings of the PAESMEM/Stanford School of Engineering Workshop, E. Riskin, M. Ostendorf, P. Cosman, M. Effros, J. Li, S. Hemami, R. M. Gray, eds., September 25, 2004, $<$ http://paesmem.stanford.edu/proceedings.pdf $>$.

${ }^{7}$ N. C. Chesler \& M. A. Chesler, "Mentoring Women Students in Engineering: Lessons Learned from the Sociology of Gender," Proc. of the 2001 ASEE Annual Conference \& Exposition.

${ }^{8}$ N. C. Chesler \& M. A. Chesler, "Gender-Informed Mentoring Strategies for Women Engineering Scholars: On Establishing a Caring Community," Journal of Engineering Education, January 2002.

${ }^{9}$ C. A. Limbert, "Chrysalis, A Peer Mentoring Group for Faculty and Staff Women,” NWSA Journal, 7(2), 1995, 86-99.

${ }^{10}$ C. Chandler, "Mentoring and Women in Academia: Reevaluating the Traditional Model," NWSA Journal, 8(3), 1996, 79-100.

${ }^{11}$ B. E. Marino \& S. A. Yost, “Optimizing Mentor/Mentee Relationships in Academia," Proc. of the 1998 ASEE Annual Conference \& Exposition.

${ }^{12}$ B. W. Packard, L. Walsh, \& S. Seidenberg, "Will that be one mentor or two? A cross-sectional study of women's mentoring during college," Mentoring and Tutoring, 12(1), 2004, 71-85.

${ }^{13}$ T. S. Harding, "Training Graduate Student Instructors Effectively: The University of Michigan Model," Proc. of the 1999 ASEE Annual Conference \& Exposition.

${ }^{14}$ J. Sprague \& J. D. Nyquist, "TA Supervision," Teaching Assistant Training in the 1990s, Nyquist et al., eds, San Francisco: Jossey Bass, 1989, 37-53.

${ }^{15}$ L. S. Williams, "The Effects of a Comprehensive Teaching Assistant Training Program on Teaching Anxiety and Effectiveness," Research in Higher Education, 32(5), 1991, 585-598.

${ }^{16}$ Criteria for Accrediting Engineering Programs, November 1, 2003, <http://www.abet.org/criteria.html >.

${ }^{17}$ Career Strategies for Women in Academe: Arming Athena, L. H. Collins, J. C. Chrisler, K. Quina, eds., Thousand Oaks, CA: SAGE Publications, 1998.

${ }^{18}$ E. Toth, Ms. Mentor's Impeccable Advice for Women in Academia, Philadelphia: University of Pennsylvania Press, 1997.

${ }^{19}$ R. Boice, Advice for New Faculty Members, Needham Heights, MA: Allyn \& Bacon, 2000.

\section{Biographical Information}

REBECCA A. BATES is an Assistant Professor in Computer and Information Sciences at Minnesota State University, Mankato and teaches engineers to program. She has a Ph.D. in Electrical Engineering from the University of Washington, an M.S. in EE and a B.S. in Biomedical Engineering from Boston University, and an M.T.S from Harvard Divinity School. Her research area is speech recognition and natural language processing. 